\title{
Somatic mutations in the GATA6 gene underlie sporadic tetralogy of Fallot
}

\author{
RI-TAI HUANG ${ }^{1}$, SONG XUE ${ }^{1}$, YING-JIA XU ${ }^{2}$ and YI-QING YANG ${ }^{3}$ \\ ${ }^{1}$ Department of Cardiothoracic Surgery, Renji Hospital, Shanghai Jiaotong University School of Medicine, \\ Shanghai 200127; Departments of ${ }^{2}$ Cardiology and ${ }^{3}$ Cardiovascular Research, Shanghai Chest Hospital, \\ Shanghai Jiaotong University School of Medicine, Shanghai 200030, P.R. China
}

Received August 27, 2012; Accepted October 22, 2012

DOI: $10.3892 /$ ijmm.2012.1188

\begin{abstract}
Tetralogy of Fallot (TOF) is the most common cyanotic congenital heart disease associated with significant morbidity and mortality in humans. However, the molecular etiology underlying TOF in most patients remains largely unknown. In the present study, sequence analysis of the GATA6 gene was performed from fresh-frozen cardiac tissues and matched blood samples of 52 unrelated patients who underwent surgical repair of TOF. The cardiac tissues and matched blood specimens from 46 patients who underwent cardiac valve replacement due to rheumatic heart disease and blood samples from 200 healthy individuals as controls were genotyped. The functional characteristics of the mutations were assessed using a luciferase reporter assay system. Based on the results, two novel heterozygous GATA6 mutations, p.G367X and p.G394C, were identified in the cardiac tissues of 2 TOF patients, respectively. No mutations were found in the cardiac tissues from 46 patients with rheumatic heart disease and in the blood samples from the 298 participants. Functional analysis demonstrated that the GATA6 mutants were consistently associated with significantly reduced transcriptional activation compared with their wildtype counterpart. This is the first report on the link of somatic GATA6 mutation to TOF, providing novel insight into the molecular mechanism involved in TOF.
\end{abstract}

\section{Introduction}

Congenital heart disease (CHD) is the most common form of birth defect in humans worldwide, affecting nearly $1 \%$ of

Correspondence to: Dr Song Xue, Department of Cardiothoracic Surgery, Renji Hospital, Shanghai Jiaotong University School of Medicine, 1630 Dongfang Road, Shanghai 200127, P.R. China

E-mail: xuesong64@163.com

Professor Yi-Qing Yang, Department of Cardiovascular Research, Shanghai Chest Hospital, Shanghai Jiaotong University School of Medicine, 241 West Huaihai Road, Shanghai 200030, P.R. China E-mail: yang99yang66@hotmail.com

Key words: congenital heart disease, tetralogy of Fallot, genetics, transcription factor, GATA6, reporter gene analysis all live births, and is the leading cause of infant mortality from developmental malformations (1). According to specific anatomic or hemodynamic lesions, CHD is clinically classified into at least 21 different types, of which tetralogy of Fallot (TOF), a tetrad of right ventricular outflow tract obstruction, over-riding of the aortic root, ventricular septal defect, and right ventricular hypertrophy, is the most prevalent type of cyanotic CHD, occurring in approximately 3 of every 10,000 neonates alive, and accounts for roughly $7-10 \%$ of all congenital cardiac abnormalities. Without surgical repair, $25 \%$ of TOF patients with severe obstruction succumb to the disease within the first year, $40 \%$ succumb to the disease by the age of $3,70 \%$ by the age of 10 , and $95 \%$ by the age of 40 (1-3). Various congenital cardiovascular anomalies, such as atrial septal defect, ventricular septal defect, atrioventricular septal defect, TOF, patent ductus arteriosus, double outlet right ventricle, aortic stenosis, and transposition of great arteries, can occur alone or together, leading to poor quality of life, cardiac enlargement or hypertrophy, ventricular dysfunction or failure, delayed fetal brain development, pulmonary hypertension, Eisenmenger's syndrome, arrhythmias, and even sudden cardiac death in the absence of surgical or catheterbased corrections (4-10). Despite the high prevalence and the important clinical significance, the etiology responsible for CHD remains to be identified in an overwhelming majority of patients (11-13).

It is generally understood that normal embryonic heart development is a complex and dynamic process that requires the orchestration of cardiac cell commitment, differentiation, proliferation and migration, and abnormal cardiac morphogenesis appears to be implicated in both environmental and genetic risk factors, which disrupt the finely regulated biological developmental process (11-13). Previous studies demonstrated that an evolutionarily conserved network of transcription factors that connect signaling pathways with genes for muscle growth, patterning, and contractility, including GATA and NK families, plays a pivotal role in early cardiogenesis (14-17), and a great number of germline mutations in NKX2-5, GATA4 and GATA6 have been associated with CHD (18-39). Nevertheless, the genetic determinants underlying CHD remain largely unclear.

Emerging evidence suggests a novel genetic mosaic mechanism for CHD. Somatic mutations have been identified 
in GATA4 and its molecular partners, NKX2-5 and TBX5, as well as the transcription factor HAND1 and HEY2 in cardiac tissue derived from hearts with CHD (40-48). GATA6 is another member of the GATA family, and its expression and function overlap at least partially with those of GATA4, NKX2-5 and TBX5 during cardiovascular genesis, which makes it logical to hypothesize that somatic GATA6 mutations are involved in the pathogenesis of TOF.

In the present study, in order to evaluate the prevalence and spectrum of somatic GATA6 mutations in patients with sporadic TOF and explore the mechanism by which mutated GATA6 predisposes to TOF, the entire coding region and splice junctions of GATA6 was sequenced in patients as comparison to control individuals, and the functional characteristics of the mutant GATA6 were assessed in comparison with its wildtype counterpart by using a luciferase reporter assay system.

\section{Materials and methods}

Study subjects. A cohort of 52 unrelated patients with TOF, who underwent cardiac surgery at Shanghai Renji Hospital in China between January 2009 and December 2011, was recruited. Their age ranged from 6 months to 7 years, with an average of 1.24 years at the time of surgery. The patients were evaluated by skillful cardiologists and the diagnosis was made by echocardiography and confirmed by direct view during surgical procedure. The patients with known chromosomal abnormalities or syndromic cardiovascular defects, such as DiGeorge, Alagille, Noonan, Holt-Oram, Marfan and Char syndrome, were excluded from the study. The sample size was adequate to draw the conclusion that the absence of somatic mutations is significant, according to the report by Draus et al (42).

A total of 46 unrelated patients ( 25 males and 21 females) with rheumatic heart disease undergoing cardiac valve replacement, and 200 unrelated healthy individuals (105 males and 95 females) randomly selected from those undergoing routine physical examinations, were enrolled as controls. In terms of individual medical history and echocardiographic record, the control individuals had no apparent congenital cardiovascular defects, except for subclinical cardiac aberrations such as bicuspid aortic valve or patent foramen ovale.

The participants were Chinese Han people. The ethnic origin of a participant was ascertained by a combination of self-reported ethnicity and a personal questionnaire regarding birthplace, language, religion and ancestry. The study protocol was reviewed and approved by the local Institutional Ethics Committee and written informed consent was obtained from all participants or their guardians prior to the study.

Sample collection and storage. The cardiac muscle tissues from the right ventricular outflow tracts of TOF patients were resected during the routine cardiac surgery procedures. At the time of resection, the discarded cardiac tissue sample was collected after cleaning the blood stain by sterile normal saline and stored at $-80^{\circ} \mathrm{C}$. Meanwhile, the patient's discarded peripheral venous blood with sodium citrate was collected (the blood samples were mostly used for activated partial thromboplastin time and prothrombin time tests before surgery). The discarded cardiac specimens from the cardiac valves and matched blood samples of the patients undergoing cardiac valve replacement due to rheumatic valvular disease, and the peripheral venous blood samples of healthy individuals were prepared as controls.

DNA extraction. The somatic DNA was extracted from freshly frozen tissues using QIAamp DNA FFPE Tissue kit (Qiagen $\mathrm{GmbH}$, Hilden, Germany) according to the manufacturer's instructions. The genomic DNA was extracted from peripheral blood lymphocytes with Wizard Genomic DNA purification kit (Promega, Madison, WI, USA).

Genetic studies. The primers for amplification of the coding exons and flanking splicing sites of the GATA6 gene were designed as previously described (39). Polymerase chain reaction (PCR) was performed in an automated Perkin-Elmer 9700 Thermal Cycler (Applied Biosystems, Foster City, CA, USA). The reaction mixture for PCR used in the present series of experiments consisted of $2 \mu \mathrm{l}$ of genomic DNA (50-100 ng/ $/ \mathrm{l}$ ), $2.5 \mu \mathrm{l}$ of $10 \mathrm{X}$ Taq Buffer, $5 \mu \mathrm{l}$ of $5 \mathrm{X}$ Q Solution, $2 \mu \mathrm{l}$ of dNTP Mixture (2.5 mM each), $0.5 \mu 1$ of each primer ( $20 \mathrm{mM}$ each), $0.25 \mu \mathrm{l}(1.25 \mathrm{U})$ of HotStar TaqDNA polymerase (Qiagen), and $12.25 \mu \mathrm{l}$ of deionized $\mathrm{H}_{2} \mathrm{O}$, with a final volume of $25 \mu \mathrm{l}$. PCR was carried out under the following conditions: pre-denaturation at $95^{\circ} \mathrm{C}$ for $15 \mathrm{~min}$, followed by 35 cycles of denaturation at $95^{\circ} \mathrm{C}$ for $1 \mathrm{~min}$, annealing at $62^{\circ} \mathrm{C}$ for $30 \mathrm{sec}$, and extension at $72^{\circ} \mathrm{C}$ for $1 \mathrm{~min}$, and final extension at $72^{\circ} \mathrm{C}$ for $10 \mathrm{~min}$. To avoid potential carry-over contamination of the PCR mixture, all reactions were performed under stringent conditions as recommended by Kwok and Higuchi (49). Amplified products were analyzed on $1 \%$ agarose gels stained with ethidium bromide and purified with QIAquick Gel Extraction kit (Qiagen). Both strands of each PCR product were sequenced with a BigDye ${ }^{\circledR}$ Terminator v3.1 Cycle Sequencing kit under an ABI PRISM 3130XL DNA Analyzer (were from Applied Biosystems). The sequencing primers were the same as previously designed for specific region amplification. The DNA sequences were analyzed with the DNA Sequencing Analysis Software v5.1 (Applied Biosystems). The sequence variation was validated by re-sequencing an independent PCR-generated amplicon from the same subject and met the standard quality control thresholds with a call rate $>99 \%$. Additionally, an identified GATA6 sequence variation was searched in the single nucleotide polymorphism (SNP) database of the National Center for Biotechnology Information to confirm the novelty (http://www.ncbi.nlm.nih.gov/SNP).

Alignment of GATA6 protein sequences across species. Multiple GATA6 protein sequences across various species were aligned using the online program of Muscle, version 3.6 (http://www. ncbi.nlm.nih.gov).

Prediction of the causative potential of a GATA6 sequence variation. The pathogenic potential of a GATA6 sequence variation was predicted by MutationTaster (an online program at http://www.mutationtaster.org), which automatically gave a probability for the variation to be either a disease-causing mutation or a benign polymorphism. Notably, the P-value used here is the probability of the correct prediction rather than the probability of error as used in t-test statistics (i.e., a value close to 1 indicates a high 'security' of the prediction). 
Table I. Clinical characteristics of the 52 unrelated patients with sporadic tetralogy of Fallot.

\begin{tabular}{|c|c|c|}
\hline Parameter & No. or mean value & Percentage or range \\
\hline Male & 28 & 54 \\
\hline Age at the initial diagnosis of tetralogy of Fallot (year) & 0.65 & $0-3$ \\
\hline Age at the time of surgery (year) & 1.25 & $0.5-7$ \\
\hline Positive family history of tetralogy of Fallot & 0 & 0 \\
\hline \multicolumn{3}{|l|}{ Distribution of various types of tetralogy of Fallot } \\
\hline Isolated tetralogy of Fallot & 33 & 63 \\
\hline Tetralogy of Fallot and bicuspid pulmonary valve & 7 & 13 \\
\hline Tetralogy of Fallot and stenosis of left pulmonary artery & 5 & 10 \\
\hline Tetralogy of Fallot and right-sided aortic arch & 2 & 4 \\
\hline Tetralogy of Fallot and atrial septal defect & 1 & 2 \\
\hline Tetralogy of Fallot and atrioventricular septal defect & 1 & 2 \\
\hline Tetralogy of Fallot and at least two other anatomical defects & 3 & 6 \\
\hline \multicolumn{3}{|l|}{ Incidence of arrhythmias } \\
\hline Atrioventricular block & 4 & 8 \\
\hline Atrial fibrillation & 2 & 4 \\
\hline \multicolumn{3}{|l|}{ Treatment } \\
\hline Surgical repair & 52 & 100 \\
\hline
\end{tabular}

Plasmids and site-directed mutagenesis. The recombinant expression plasmid pcDNA3-hGATA6 was kindly provided by Dr Angela Edwards-Ghatnekar, from the Division of Rheumatology and Immunology, Medical University of South Carolina, Charleston, SC, USA. The atrial natriuretic factor (ANF)-luciferase reporter gene, which contains the 2600-bp 5'-flanking region of the ANF gene, i.e., ANF(-2600)-Luc, was kindly provided by Dr Ichiro Shiojima, from the Department of Cardiovascular Science and Medicine, Chiba University Graduate School of Medicine, Chuo-ku, Chiba, Japan. The identified mutation was introduced into the wild-type GATA6 using a QuickChange II XL Site-Directed Mutagenesis kit (Stratagene, La Jolla, CA, USA) with a complementary pair of primers. The mutant was sequenced to confirm the desired mutation and to exclude any other sequence variations.

Reporter gene assay. HEK-293 cells were cultured in Dulbecco's modified Eagle's medium supplemented with $10 \%$ fetal calf serum. The ANF(-2600)-Luc reporter vector and an internal control reporter plasmid pGL4.75 (hRluc/CMV, Promega) were used in transient transfection assays to evaluate the transcriptional activation function of the GATA6 mutants. HEK-293 cells were transfected with $0.4 \mu \mathrm{g}$ of wild-type or mutant pcDNA3hGATA6 expression vector, $0.4 \mu \mathrm{g}$ of ANF(-2600)-Luc reporter construct, and $0.04 \mu \mathrm{g}$ of pGL4.75 control reporter vector using Lipofectamine ${ }^{\circledR} 2000$ Transfection reagent (Invitrogen, Carlsbad, CA, USA). For co-transfection experiments, $0.2 \mu \mathrm{g}$ of wild-type pcDNA3-hGATA6, $0.2 \mu \mathrm{g}$ of empty pcDNA3 plasmid or $0.2 \mu \mathrm{g}$ of mutant pcDNA3-hGATA6, $0.4 \mu \mathrm{g}$ of ANF(-2600)-Luc, and $0.04 \mu \mathrm{g}$ of pGL4.75 were used. Firefly luciferase and Renilla luciferase activities were measured with the Dual-Glo luciferase assay system (Promega) $48 \mathrm{~h}$ after transfection. The activity of the ANF promoter was presented as fold activation of Firefly luciferase relative to Renilla luciferase. Three independent experiments were performed at minimum for wild-type and mutant GATA6.

Statistical analysis. Data are expressed as the means \pm SD. Continuous variables were examined for normality of distribution and the Student's unpaired t-test was used for the comparison of numeric variables between two groups. A comparison of the categorical variables between two groups was conducted using Pearson's $\chi^{2}$ test or Fisher's exact test when appropriate. A two-tailed P-value $<0.05$ was considered to indicate a statistically significant difference.

\section{Results}

Baseline characteristics of the study population. A cohort of 52 unrelated Han-nationality patients with sporadic TOF, who underwent cardiac surgery, was enrolled and clinically evaluated as comparison to 46 unrelated Han-race patients with rheumatic heart disease undergoing cardiac valve replacement and 200 ethnically matched, unrelated healthy individuals used as controls. The subjects had neither positive family history of CHD nor established environmental risk factors for CHD, such as maternal illness and drug use in the first trimester of pregnancy, parental smoking, and chronic exposure to toxicants and ionizing radiation. The baseline clinical characteristics of the study population are summarized in Table I.

Source of samples. Peripheral venous blood samples were available for all 298 participants. The malformed myocardial tissue samples were obtained from 52 unrelated patients with sporadic TOF who underwent surgical resection of the right ventricular outflow musculature for relieving the stenosis. Generally, the cardiac muscle fragment obtained was $\sim 5 \times 5 \mathrm{~mm}$ in size. In addition, the cardiac valvular tissue samples used as 


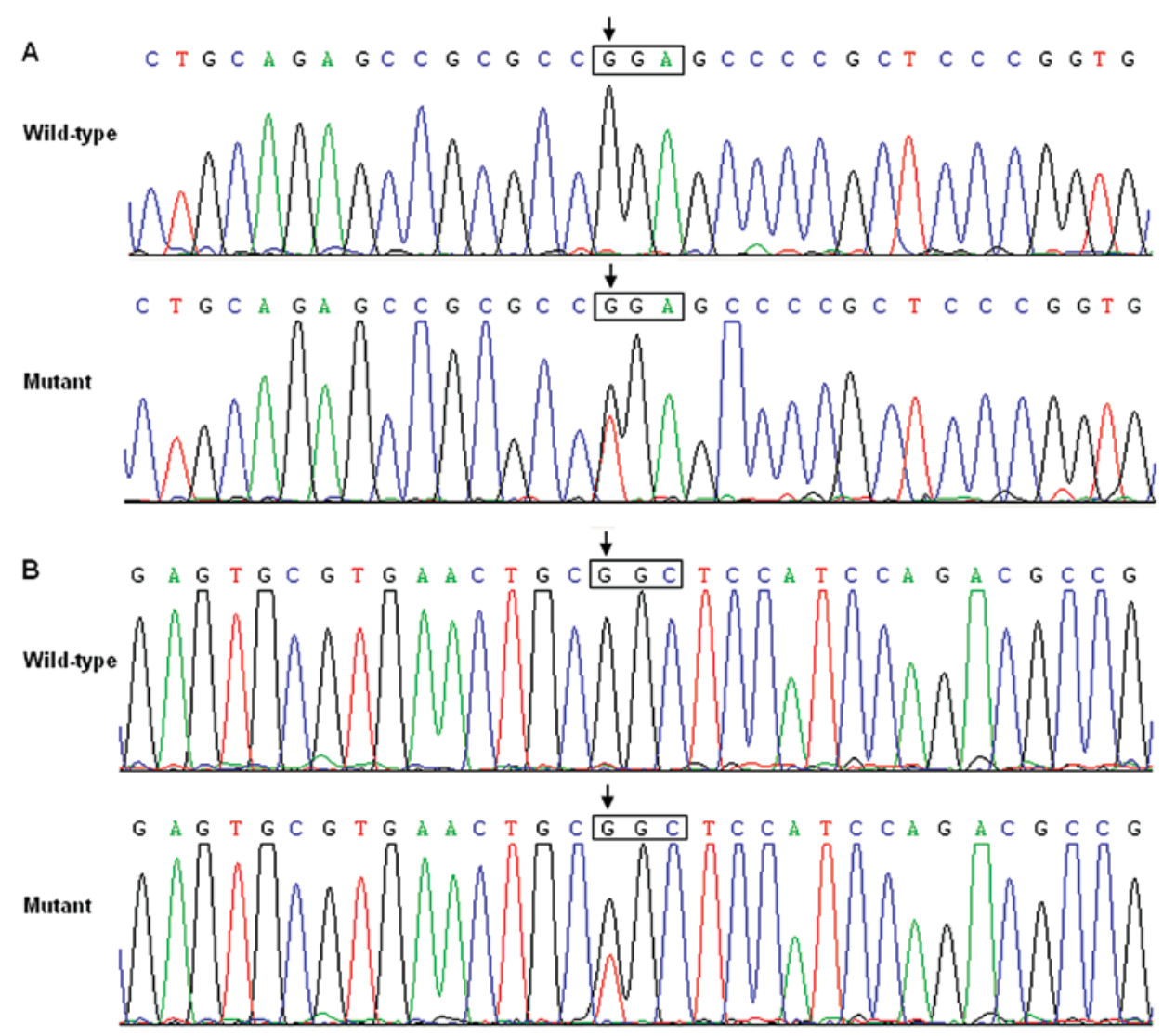

Figure 1. Sequence electropherograms showing the GATA6 mutations as comparison to their corresponding controls. The arrow indicates the heterozygous nucleotides of G/T in the 2 unrelated patients, respectively (mutant) or the homozygous nucleotides of G/G in the corresponding control individuals (wild-type). The square denotes the nucleotides comprising a codon of GATA6.

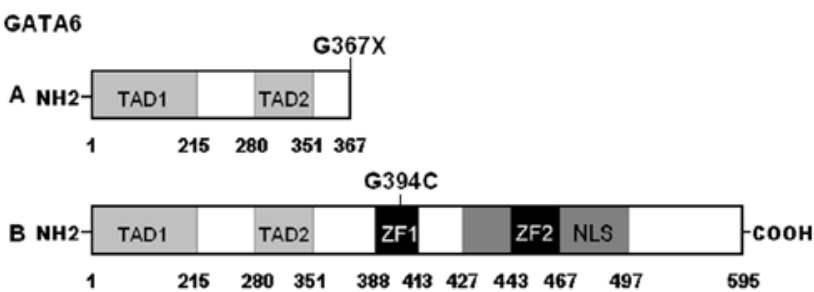

Figure 2. Schematic representation of GATA6 protein structure with the tetralogy of Fallot related mutations indicated. The mutations identified in patients with tetralogy of Fallot are shown above the structural domains. $\mathrm{NH} 2$, amino-terminus; TAD, transcriptional activation domain; $\mathrm{ZF}$, zinc finger; NLS, nuclear localization signal; and $\mathrm{COOH}$, carboxyl-terminus.

controls were obtained from surgical discards of 46 unrelated patients undergoing cardiac valve replacement.

GATA6 mutations. Genomic DNA from the malformed cardiac tissues of 52 TOF patients, the cardiac valvular tissues of 46 patients with rheumatic heart disease, and the peripheral blood lymphocytes of the 298 participants, were screened for GATA6 mutations. As a result, 2 heterozygous mutations in GATA6 were identified in the fresh pathological myocardial tissues of 2 TOF patients, respectively, with a mutational prevalence of $\sim 3.85 \%$. Specifically, a substitution of thymine for guanine in the first nucleotide of codon 367 of the GATA6 gene $(\mathrm{c} .1099 \mathrm{G}>\mathrm{T})$, resulting in a truncated protein with only
N-terminal 366 amino acids left (p.G367X), was identified in the cardiac tissue of a 1-year-old male TOF patient. A replacement of guanine by thymine at coding nucleotide 1180 (c.1180G $>\mathrm{T}$ ), predicting the transition of glycine to cysteine at amino acid position 394 (p.G394C), was identified in the cardiac tissue of a 2-year-old female TOF patient. The sequence chromatograms showing the detected heterozygous GATA6 mutations as comparison to corresponding control sequences are depicted in Fig. 1. A schematic diagram of GATA6 showing the structural domains and the locations of the identified mutations is presented in Fig. 2. The 2 mutations were neither observed in the cardiac valvular tissues of 46 patients with rheumatic heart disease nor found in the peripheral blood samples of the 298 participants. Neither of the 2 mutations was reported in the SNP database at the National Center for Biotechnology Information, which was consulted again on August 20, 2012. Additionally, during a 24-h period of ambulatory electrocardiographic monitoring, no atrial fibrillation was observed in these 2 mutation carriers.

Alignment of multiple GATA6 protein sequences. A crossspecies alignment of multiple GATA6 protein sequences demonstrated that the affected amino acid p.G394 was completely conserved evolutionarily and the affected amino acid p.G367 was relatively conserved evolutionarily (Fig. 3). However, the amino acids deleted by the p.G367X mutation constitute functionally important structural domains, including 2 zinc fingers and 1 nuclear localization signal (Fig. 2). 


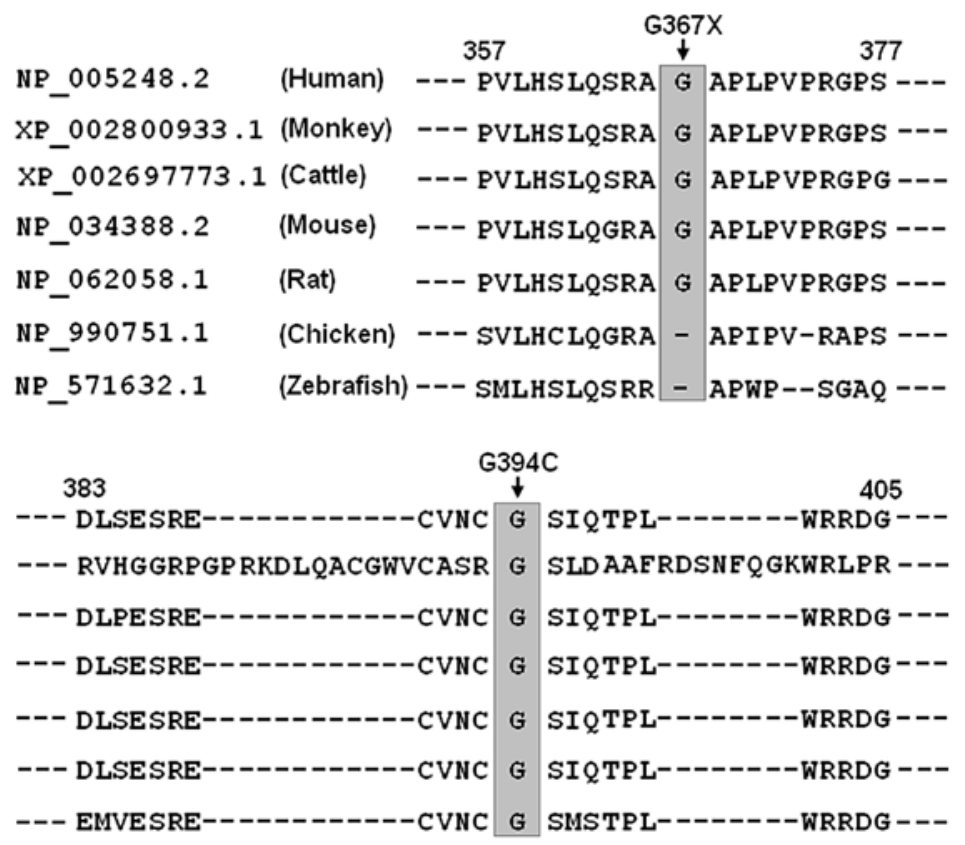

Figure 3. Multiple alignments of GATA6 protein sequences across various species. The altered amino acid, p.G394, is completely conserved evolutionarily. The P.G367X mutation resulted in a truncated protein without functionally important domains including 2 zinc fingers and 1 nuclear localization signal.

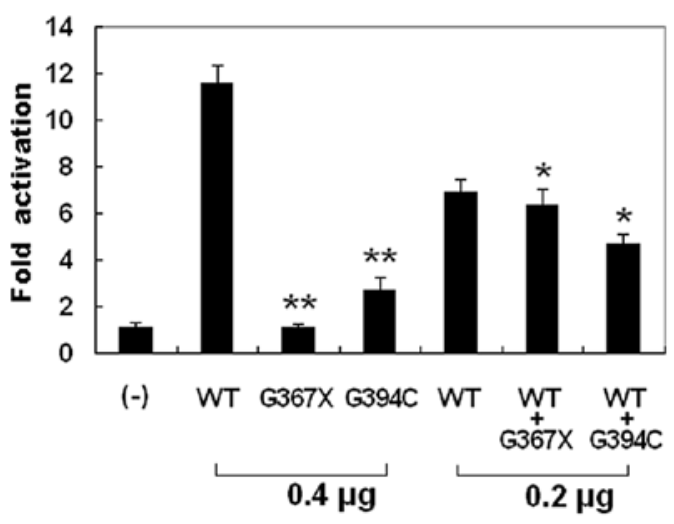

Figure 4. Functional defects associated with GATA6 mutations. Activation of ANF-luciferase reporter in HEK-293 cells by GATA6 wild-type (WT) mutant G367X or mutant G394C, alone or in combination, demonstrated significantly reduced transactivational activity by mutant proteins. Experiments were performed in triplicate and mean \pm standard deviations are shown. ${ }^{* *} \mathrm{P}<0.001$ and ${ }^{*} \mathrm{P}<0.01$, compared with wild-type GATA6.

Causative potential of GATA6 mutations. The GATA6 mutations of c.1099G $>\mathrm{T}$ and c.1180G $>\mathrm{T}$ were both automatically predicted to be disease-causing, with P-values of 1.000000 and 0.999997, respectively. No SNPs in the altered regions were found in the MutationTaster database.

Transcriptional activity of the GATA6 mutants. The wild-type GATA6, the G367X-mutant, and the G394C-mutant GATA6 activated the ANF promoter by $\sim 12-, 1$ - and 3 -fold, respectively. When wild-type GATA6 was co-expressed with the same amount of G367X-mutant or G394C-mutant GATA6, the induced activation of the ANF promoter was $~ 6-$ or 5-fold, respectively. These results indicate that both GATA6 mutants are associated with significantly reduced activation activity compared with their wild-type counterpart (Fig. 4).

\section{Discussion}

Somatic cell is defined as any cell, other than a germ cell, which is involved in the formation of the body, differentiating into the various tissues, organs. Mutations derived from somatic cells can occur in people, but are not transmitted to offspring (50). Diseases associated or causing somatic mutations can be identified by exploring the genetic substance from diseased tissue cells as comparison to that from healthy tissue cells. Somatic mutations can not be detected by genetic analysis of lymphocytic DNA alone, and mosaicism may reduce the likelihood of detection in the affected tissue. Therefore, mutations in cardiac tissues may be absent or sporadic in blood lymphocytes of the same person (40). In the present study, 2 novel heterozygous mutations of GATA6 (p.G367X and p.G394C) were identified in the malformed heart tissues of 2 out of 52 patients with TOF. The mutant alleles were absent in the cardiac tissues of 46 patients with rheumatic heart disease and in the peripheral blood samples of the 298 participants, including 200 ethnically matched healthy individuals. A cross-species alignment of multiple GATA6 protein sequences showed that the altered amino acids were highly conserved evolutionarily. The 2 variants were both predicted to be pathogenic, and the functional experiments substantiated that the mutant GATA6 proteins were associated with significantly decreased or absent transcriptional activity. Therefore, somatic GATA6 mutations may contribute to the pathogenesis of TOF in the 2 mutationharboring patients.

The GATA6 gene, mapped to human chromosome 18q11.1-q11.2 by fluorescence in situ hybridization (a powerful cytogenetic technique used to detect and localize the specific DNA sequences on chromosomes), encodes a zinc fingercontaining protein with 595 amino acids (51). By alignment of GATA6 with GATA4, the structural domains of GATA6 comprise 2 transcriptional activation domains (TAD1, amino 
acids 1-215; TAD2, amino acids 280-351), 2 adjacent zinc fingers (ZF1, amino acids 388-413; ZF2, amino acids 443-467), and 1 nuclear localization signal (NLS, amino acids 427-497). The two TADs are both essential for the transcriptional activity of GATA6. The C-terminal ZF1 is required for DNA sequence recognition and binding to the consensus motif, while the $\mathrm{N}$-terminal ZF2 is responsible for sequence specificity and stability of protein-DNA binding. The NLS is associated with the sub-cellular trafficking and distribution of GATA6 (39). The GATA6 mutation p.G367X eliminates the functionally pivotal domains of ZF1, ZF2 and NLS as well as the carboxyl terminus, and may thus be expected to nullify the function of GATA6. Another GATA6 mutation p.G394C identified in this study is located at ZF1, hence it is likely to induce loss of transcriptional activity of GATA6 by interfering with the specific binding of GATA6 to target gene promoters.

GATA6 is an upstream transcriptional regulator of multiple genes expressed during embryogenesis and cardiac morphogenesis, including the genes that encode atrial natriuretic factor (ANF), brain natriuretic peptide, $\alpha$-myosin heavy chain, $\beta$ myosin heavy chain, and gap junction protein connexin-40 (52). Therefore, the functional characteristics of the GATA6 mutations may be delineated by assessing the transcriptional activity of the $A N F$ promoter in cultured cells. In this study, the functional effect of the novel GATA6 mutations identified in TOF patients was characterized by transcriptional activation assay, and the results showed a significantly decreased transcriptional activity on a downstream gene. These data suggest that dysfunctional GATA6 caused by loss-of-function mutations is potentially an alternative pathogenic mechanism implicated in TOF.

It has previously been reported that germline mutations of the GATA6 gene are responsible for CHD, including TOF. Kodo et al scanned GATA6 in 21 unrelated patients with persistent truncus arteriosus, and identified 2 heterozygous mutations of p.E486GfsX10 and p.N466H in 2 patients, respectively, with a prevalence of $9.52 \%$. Functional analysis demonstrated both GATA6 mutations led to defects in nuclear localization and transcription activity (36). Lin et al (37) performed sequence analysis of GATA6 in 270 unrelated patients with CHD, and detected a novel heterozygous mutation of p.S184N in 3 unrelated patients, including 1 with TOF and 2 with atrial septal defect, with a prevalence of $1.11 \%$. Biochemical assays unveiled that the mutation had significantly decreased transcriptional activity. Maitra et al (38) genotyped GATA6 in 310 unrelated patients with CHD and 2 heterozygous mutations of p.A178V and p.L198V were identified in 2 patients, respectively, with a prevalence of $0.65 \%$. The p.L198V carrier was affected with TOF whereas the p.A178V carrier was affected with atrioventricular septal defect, hypoplastic left ventricle, and ventricular septal defect. Functional evaluation revealed the p.A178V mutation had increased transcriptional activity while the p.L198V mutation had no effect on the transcriptional activity. Zheng et al (39) made mutational analysis of GATA6 in 130 unrelated patients with ventricular septal defect, and found a loss-of-function mutation p.G220S in a patient, with a mutation prevalence of $0.77 \%$. To date, 6 germline GATA6 mutations have been identified in 8 of 731 index patients with CHD, with a total mutation prevalence of $1.09 \%$ (36-39). However, in the current study, no germline GATA6 mutations were discovered except that 2 somatic GATA6 mutations were found, which highlights a genetic mosaic basis for TOF in a subset of cases.

Association of functionally compromised GATA6 with enhanced vulnerability to CHD has been revealed in animals. Homozygous GATA6 knockout mice die shortly after embryonic implantation due to defects in visceral endoderm function and extra-embryonic development $(53,54)$. Although the mice heterozygous for either GATA4 or GATA6 deletion are viable without overt cardiovascular defects, the mice that are compound heterozygous for both GATA4 and GATA6 targeted disruptions die by E13.5 with $100 \%$ penetrance, exhibiting a phenotypic spectrum of cardiovascular defects, including ventricular septal defect, persistent truncus arteriosus, myocardial hypoplasia, reduced myocardial proliferation, and impaired differentiation of vascular smooth muscle cells (53-55). Similarly, compound null of a GATA5 and a GATA6 allele also gives rise to double outlet right ventricle and ventricular septal defect in mice (56). These results from experimental animals demonstrate an exquisite sensitivity of the developing cardiovascular system to the levels of GATA4, GATA5 and GATA6, and indicate that these GATA factors act synergistically to regulate downstream target genes.

Atrial fibrillation has been documented in some CHD patients harboring the germline mutations of GATA4, GATA5 and GATA6 (57-64), which suggests that atrial fibrillation may share a common genetic origin with CHD. However, in the current investigation, no atrial fibrillation was documented in the 2 somatic GATA6 mutation carriers, which may be explained by insufficient electrocardiographic monitoring duration of only $24 \mathrm{~h}$ for paroxysmal AF, different genetic background, distinct mutational source, delayed or incomplete penetrance, epigenetic modifiers, or environmental factors (61).

In conclusion, this is the first report on the association of somatic GATA6 loss-of-function mutation with increased susceptibility to TOF, which provides novel insight into the molecular pathogenesis of CHD, and suggests the potential implications for the early diagnosis and personalized treatment of CHD.

\section{Acknowledgements}

The authors thank the participants for their devotion to the study. This study was supported in part by grants from the National Natural Science Foundation of China (81270161, 81070153 and 30570768), the Personnel Development Foundation of Shanghai, China (2010019), the Natural Science Foundation of Shanghai, China (10ZR1428000), and the Key Program of Basic Research of Shanghai, China (10JC1414002).

\section{References}

1. Roger VL, Go AS, Lloyd-Jones DM, Benjamin EJ, Berry JD, Borden WB, Bravata DM, Dai S, Ford ES, Fox CS, Fullerton HJ, Gillespie C, Hailpern SM, Heit JA, Howard VJ, Kissela BM, Kittner SJ, Lackland DT, Lichtman JH, Lisabeth LD, Makuc DM, Marcus GM, Marelli A, Matchar DB, Moy CS, Mozaffarian D, Mussolino ME, Nichol G, Paynter NP, Soliman EZ, Sorlie PD, Sotoodehnia N, Turan TN, Virani SS, Wong ND, Woo D and Turner MB; American Heart Association Statistics Committee and Stroke Statistics Subcommittee. Heart disease and stroke statistics - 2012 update: a report from the American Heart Association. Circulation 125: e2-e220, 2012. 
2. van der Linde D, Konings EE, Slager MA, Witsenburg M, Helbing WA, Takkenberg JJ and Roos-Hesselink JW: Birth prevalence of congenital heart disease worldwide: a systematic review and meta-analysis. J Am Coll Cardiol 58: 2241-2247, 2011.

3. Starr JP: Tetralogy of Fallot: yesterday and today. World J Surg 34: 658-668, 2010.

4. Müller J, Hess J and Hager A: Exercise performance and quality of life is more impaired in Eisenmenger syndrome than in complex cyanotic congenital heart disease with pulmonary stenosis. Int J Cardiol 150: 177-181, 2011.

5. Teixeira FM, Coelho RM, Proença C, Silva AM, Vieira D, Vaz C, Moura C, Viana V, Areias JC and Areias ME: Quality of life experienced by adolescents and young adults with congenital heart disease. Pediatr Cardiol 32: 1132-1138, 2011.

6. Müller J, Hess J and Hager A: Minor symptoms of depression in patients with congenital heart disease have a larger impact on quality of life than limited exercise capacity. Int J Cardiol 154 265-269, 2012.

7. Shedeed SA and Elfaytouri E: Brain maturity and brain injury in newborns with cyanotic congenital heart disease. Pediatr Cardiol 32: 47-54, 2011

8. Perry JC: Sudden cardiac death and malignant arrhythmias: the scope of the problem in adult congenital heart patients. Pediatr Cardiol 33: 484-490, 2012

9. Silka MJ and Bar-Cohen Y: A contemporary assessment of the risk for sudden cardiac death in patients with congenital heart disease. Pediatr Cardiol 33: 452-460, 2012.

10. Cheng HH, Almodovar MC, Laussen PC, Wypij D, Polito A, Brown DW, Emani SM, Pigula FA, Allan CK and Costello JM: Outcomes and risk factors for mortality in premature neonates with critical congenital heart disease. Pediatr Cardiol 32: 1139-1146, 2011.

11. Bruneau BG: The developmental genetics of congenital heart disease. Nature 451: 943-948, 2008

12. Cecchetto A, Rampazzo A, Angelini A, Bianco LD, Padalino M, Stellin G and Daliento L: From molecular mechanisms of cardiac development to genetic substrate of congenital heart diseases. Future Cardiol 6: 373-393, 2010.

13. Benson DW: Genetic origins of pediatric heart disease. Pediatr Cardiol 31: 422-429, 2010.

14. Olson EN: Gene regulatory networks in the evolution and development of the heart. Science 313: 1922-1927, 2006.

15. Hu DL, Chen FK, Liu YQ, Sheng YH, Yang R, Kong XQ, Cao KJ, Gu HT and Qian LM: GATA-4 promotes the differentiation of P19 cells into cardiac myocytes. Int J Mol Med 26: 365-372, 2010

16. Pikkarainen S, Tokola H, Kerkelä R and Ruskoaho H: GATA transcription factors in the developing and adult heart. Cardiovasc Res 63: 196-207, 2004.

17. Bartlett H, Veenstra GJ and Weeks DL: Examining the cardiac NK-2 genes in early heart development. Pediatr Cardiol 31 335-341, 2010.

18. Schott JJ, Benson DW, Basson CT, Pease W, Silberbach GM Moak JP, Maron BJ, Seidman CE and Seidman JG: Congenital heart disease caused by mutations in the transcription factor NKX2-5. Science 281: 108-111, 1998

19. Wang J, Xin YF, Liu XY, Liu ZM, Wang XZ and Yang YQ: A novel NKX2-5 mutation in familial ventricular septal defect. Int J Mol Med 27: 369-375, 2011

20. Garg V, Kathiriya IS, Barnes R, Schluterman MK, King IN Butler CA, Rothrock CR, Eapen RS, Hirayama-Yamada K, Joo K, Matsuoka R, Cohen JC and Srivastava D: GATA4 mutations cause human congenital heart defects and reveal an interaction with TBX5. Nature 424: 443-447, 2003.

21. Okubo A, Miyoshi O, Baba K, Takagi M, Tsukamoto K, Kinoshita A, Yoshiura K, Kishino T, Ohta T, Niikawa N and Matsumoto N: A novel GATA4 mutation completely segregated with atrial septal defect in a large Japanese family. J Med Genet 41: e97, 2004.

22. Sarkozy A, Conti E, Neri C, D'Agostino R, Digilio MC,Esposito G, Toscano A, Marino B, Pizzuti A and Dallapiccola B: Spectrum of atrial septal defects associated with mutations of NKX2.5 and GATA4 transcription factors. J Med Genet 42: e16, 2005.

23. Hirayama-Yamada K, Kamisago M, Akimoto K, Aotsuka H, Nakamura Y, Tomita H, Furutani M, Imamura S, Takao A, Nakazawa M and Matsuoka R: Phenotypes with GATA4 or NKX2.5 mutations in familial atrial septal defect. Am J Med Genet A 135: 47-52, 2005.

24. Nemer G, Fadlalah F, Usta J, Nemer M, Dbaibo G, Obeid M and Bitar F: A novel mutation in the GATA4 gene in patients with tetralogy of Fallot. Hum Mutat 27: 293-294, 2006.
25. Tomita-Mitchell A, Maslen CL, Morris CD, Garg V and Goldmuntz E: GATA4 sequence variants in patients with congenital heart disease. J Med Genet 44: 779-783, 2007.

26. Rajagopal SK, Ma Q, Obler D, Shen J, Manichaikul A, TomitaMitchell A, Boardman K, Briggs C, Garg V, Srivastava D, Goldmuntz E, Broman KW, Benson DW, Smoot LB and Pu WT: Spectrum of heart disease associated with murine and human GATA4 mutation. J Mol Cell Cardiol 43: 677-685, 2007.

27. Zhang W, Li X, Shen A, Jiao W, Guan X and Li Z: GATA4 mutations in 486 Chinese patients with congenital heart disease. Eur J Med Genet 51: 527-535, 2008

28. Hamanoue H, Rahayuningsih SE, Hirahara Y, Itoh J, Yokoyama U, Mizuguchi T, Saitsu H, Miyake N, Hirahara F and Matsumoto N: Genetic screening of 104 patients with congenitally malformed hearts revealed a fresh mutation of GATA4 in those with atrial septal defects. Cardiol Young 19: 482-485, 2009.

29. Chen MW, Pang YS, Guo Y, Pan JH, Liu BL, Shen J and Liu TW: GATA4 mutations in Chinese patients with congenital cardiac septal defects. Pediatr Cardiol 31: 85-89, 2010.

30. Chen Y, Mao J, Sun Y, Zhang Q, Cheng HB, Yan WH, Choy KW and $\mathrm{Li} \mathrm{H}$ : A novel mutation of GATA4 in a familial atrial septal defect. Clin Chim Acta 411: 1741-1745, 2010.

31. Butler TL, Esposito G, Blue GM, Cole AD, Costa MW, Waddell LB, Walizada G, Sholler GF, Kirk EP, Feneley M, Harvey RP and Winlaw DS: GATA4 mutations in 357 unrelated patients with congenital heart malformation. Genet Test Mol Biomarkers 14: 797-802, 2010.

32. Liu XY, Wang J, Zheng JH, Bai K, Liu ZM, Wang XZ, Liu X, Fang WY and Yang YQ: Involvement of a novel GATA4 mutation in atrial septal defects. Int J Mol Med 28: 17-23, 2011.

33. Wang J, Fang M, Liu XY, Xin YF, Liu ZM, Chen XZ, Wang XZ, Fang WY, Liu XS and Yang YQ: A novel GATA4 mutation responsible for congenital ventricular septal defects. Int J Mol Med 28: 557-564, 2011.

34. Yang YQ, Li L, Wang J, Liu XY, Chen XZ, Zhang W, Wang XZ, Jiang JQ, Liu XS and Fang WY: A novel GATA4 loss-of-function mutation associated with congenital ventricular septal defect. Pediatr Cardiol 33: 539-546, 2012

35. Yang YQ, Wang J, Liu XY, Chen XZ, Zhang W, Wang XZ, Liu XS and Fang WY: Novel GATA4 mutations in patients with congenital ventricular septal defects. Med Sci Monit 18: CR344-CR350, 2012.

36. Kodo K, Nishizawa T, Furutani M, Arai S, Yamamura E, Joo K, Takahashi T, Matsuoka RS and Yamagishi H: GATA6 mutations cause human cardiac outflow tract defects by disrupting semaphorin-plexin signaling. Proc Natl Acad Sci USA 106 13933-13938, 2009.

37. Lin X, Huo Z, Liu X, Zhang Y, Li L, Zhao H, Yan B, Liu Y, Yang YS and Chen YH: A novel GATA6 mutation in patients with tetralogy of Fallot or atrial septal defect. J Hum Genet 55: 662-667, 2010.

38. Maitra M, Koenig SN, Srivastava DS and Garg V: Identification of GATA6 sequence variants in patients with congenital heart defects. Pediatr Res 68: 281-285, 2010

39. Zheng GF, Wei D, Zhao H, Zhou N, Yang YQ and Liu XY: A novel GATA6 mutation associated with congenital ventricular septal defect. Int J Mol Med 29: 1065-1071, 2012.

40. Reamon-Buettner SM and Borlak J: Somatic NKX2-5 mutations as a novel mechanism of disease in complex congenital heart disease. J Med Genet 41: 684-690, 2004.

41. Reamon-Buettner SM, Hecker H, Spanel-Borowski K, Craatz S, Kuenzel ES and Borlak J: Novel NKX2-5 mutations in diseased heart tissues of patients with cardiac malformations. Am J Pathol 164: 2117-2125, 2004.

42. Draus JM Jr, Hauck MA, Goetsch M, Austin EH III, TomitaMitchell AS and Mitchell ME: Investigation of somatic NKX2-5 mutations in congenital heart disease. J Med Genet 46: 115-122, 2009.

43. Reamon-Buettner SM and Borlak J: GATA4 zinc finger mutations as a molecular rationale for septation defects of the human heart. J Med Genet 42: e32, 2005.

44. Reamon-Buettner SM, Cho SH and Borlak J: Mutations in the 39-untranslated region of GATA4 as molecular hotspots for congenital heart disease (CHD). BMC Med Genet 8: 38, 2007.

45. Salazar M, Consoli F, Villegas V, Caicedo V, Maddaloni V, Daniele P, Caianiello G, Pachón S, Nuñez F, Limongelli G, Pacileo G, Marino B, Bernal JE, De Luca AS and Dallapiccola B: Search of somatic GATA4 and NKX2.5 gene mutations in sporadic septal heart defects. Eur J Med Genet 54: 306-309, 2011.

46. Reamon-Buettner SM and Borlak J: TBX5 mutations in nonHolt-Oram syndrome (HOS) malformed hearts. Hum Mutat 24: $104,2004$. 
47. Wang J, Lu Y, Chen H, Yin M, Yu TS and Fu Q: Investigation of somatic NKX2-5, GATA4 and HAND1 mutations in patients with tetralogy of Fallot. Pathology 43: 322-326, 2011.

48. Reamon-Buettner SM and Borlak J: HEY2 mutations in malformed hearts. Hum Mutat 27: 118, 2006.

49. Kwok S and Higuchi R: Avoiding false positives with PCR. Nature 339: 237-238, 1989.

50. Feero WG, Guttmacher AE and Collins FS: Genomic medicine an updated primer. N Engl J Med 362: 2001-2011, 2010.

51. Suzuki E, Evans T, Lowry J, Truong L, Bell DW, Testa JR and Walsh K: The human GATA-6 gene: structure, chromosomal location, and regulation of expression by tissue-specific and mitogen-responsive signals. Genomics 38: 283-290, 1996.

52. Rémond MC, Iaffaldano G, O'Quinn MP, Mezentseva NV, Garcia V, Harris BS, Gourdie RG, Eisenberg CA and Eisenberg LM: GATA6 reporter gene reveals myocardial phenotypic heterogeneity that is related to variations in gap junction coupling. Am J Physiol Heart Circ Physiol 301: H1952-H1964, 2011.

53. Zhao R, Watt AJ, Battle MA, Li J, Bondow BJ and Duncan SA: Loss of both GATA4 and GATA6 blocks cardiac myocyte differentiation and results in acardia in mice. Dev Biol 317: 614-619, 2008.

54. Morrisey EE, Tang Z, Sigrist K, Lu MM, Jiang F, Ip HS, Parmacek MS: GATA6 regulates HNF4 and is required for differentiation of visceral endoderm in the mouse embryo. Genes Dev 12: 3579-3590, 1998.

55. Xin M, Davis CA, Molkentin JD, Lien CL, Duncan SA Richardson JA and Olson EN: A threshold of GATA4 and GATA6 expression is required for cardiovascular development. Proc Natl Acad Sci USA 103: 11189-11194, 2006.

56. Laforest B and Nemer M: GATA5 interacts with GATA4 and GATA6 in outflow tract development. Dev Biol 358: 368-378, 2011.
57. Jiang JQ, Shen FF, Fang WY, Liu X and Yang YQ: Novel GATA4 mutations in lone atrial fibrillation. Int J Mol Med 28: 1025-1032, 2011.

58. Wang J, Sun YM and Yang YQ: Mutation spectrum of the GATA4 gene in patients with idiopathic atrial fibrillation. Mol Biol Rep 39: 8127-8135, 2012.

59. Yang YQ, Wang MY, Zhang XL, Tan HW, Shi HF, Jiang WF, Wang XH, Fang WY and Liu X: GATA4 loss-of-function mutations in familial atrial fibrillation. Clin Chim Acta 412: 1825-1830, 2011.

60. Posch MG, Boldt LH, Polotzki M, Richter S, Rolf S, Perrot A, Dietz R, Ozcelik C and Haverkamp W: Mutations in the cardiac transcription factor GATA4 in patients with lone atrial fibrillation. Eur J Med Genet 53: 201-203, 2010.

61. Yang YQ, Wang J, Wang XH, Wang Q, Tan HW, Zhang M, Shen FF, Jiang JQ, Fang WY and Liu X: Mutational spectrum of the GATA5 gene associated with familial atrial fibrillation. Int J Cardiol 157: 305-307, 2012

62. Yang YQ, Wang XH, Tan HW, Jiang WF, Fang WY and Liu X: Prevalence and spectrum of GATA6 mutations associated with familial atrial fibrillation. Int J Cardiol 155: 494-496, 2012.

63. Yang YQ, Li L, Wang J, Zhang XL, Li RG, Xu YJ, Tan HW, Wang XH, Jiang JQ, Fang WY and Liu X: GATA6 loss-offunction mutation in atrial fibrillation. Eur J Med Genet 55: 520-526, 2012.

64. Li J, Liu WD, Yang ZL and Yang YQ: Novel GATA6 loss-offunction mutation responsible for familial atrial fibrillation. Int $\mathrm{J}$ Mol Med 30: 783-790, 2012. 